\title{
Tensões epistemológicas na Bibliografia e na Documentação: os diferentes olhares de Otlet e Ranganathan
}

\author{
Epistemological tensions in Bibliography and Documentation: the different views of Otlet and \\ Ranganathan
}

Igor Soares Amorim Doutor em Ciência da Informação pela Universidade Federal de Santa Catarina - UFSC, Brasil. Professor substituto da Universidade do Estado de Santa Catarina - UDESC, Brasil E-mail: amorim.igors@gmail.com Rodrigo de Sales
Doutor em Ciência da Informação pela Universidade Estadual Paulista Júlio de Mesquita Filho, Brasil.
Professor Adjunto da Universidade Federal de Santa Catarina, Brasil.
E-mail: rodrigo.sales.s@ gmail.com

\section{Resumo}

A compreensão epistemológica a respeito da Bibliografia e da Documentação apresenta perspectivas distintas quanto à natureza das mesmas. Vistas concomitantemente como atividades e como disciplinas, Bibliografia e Documentação foram abordadas de formas diferentes por importantes pensadores do campo informacional, especialmente por Otlet e Ranganathan. Neste contexto, apresentamos um estudo que teve por objetivo investigar a compreensão que Otlet e Ranganathan tiveram a respeito da Bibliografia e da Documentação e como ambos as relacionaram com a Biblioteconomia. Do ponto de vista metodológico, foi realizada uma análise comparativa entre as obras Traité de Documentation (1934), de Otlet, e os livros Social Bibliography or Phisical Bibliography for Librarians (1952) e Documentation: Genesis and Development (1973), de Ranganathan. Os resultados apontaram que, para Otlet, Bibliografia e Documentação eram diferentes estágios de um movimento científico evolutivo que avançara de uma dimensão processual para uma dimensão metodológico-científica, desligando-se da Biblioteconomia e se inserindo na chamada Bibliologia. Para Ranganathan, a Documentação era um conjunto de atividades análogas à catalogação e ao serviço de referência (atividades biblioteconômicas) e a Bibliografia, dotada de maior cientificidade que a Documentação, estava voltada à produção bibliográfica e seu papel na comunicação social, alicerçada também pela Biblioteconomia. Concluímos que o discurso emancipatório de Otlet abriu espaço para a instauração de uma ciência do documento (Documentação), ao passo que o discurso de Ranganathan conferiu autoridade científica à Biblioteconomia para lidar tanto com a Documentação quanto com a Bibliografia.

Palavras-chave: Bibliografia. Documentação. Otlet. Ranganathan. Biblioteconomia.

\begin{abstract}
The epistemological understanding of Bibliography and Documentation presents different perspectives regarding their natures. Seen both as activities and as disciplines, Bibliography and Documentation were approached in different ways by important thinkers in the informational field, especially by Otlet and Ranganathan. In this context, we present a study that aimed to investigate the understanding that Otlet and Ranganathan had of Bibliography and Documentation and how they both related them to Library Science. From a methodological point of view, a comparative analysis was carried out between Otlet's Traité de Documentation (1934) and Ranganathan's Social Bibliography or Physical Bibliography for Librarians (1952) and Documentation: Genesis and Development (1973). The results showed that, for Otlet, Bibliography and Documentation were different stages of an evolutionary scientific movement that had moved from a procedural dimension to a methodological-scientific dimension, disconnecting from Library Science and entering the so-called Bibliology. Ranganathan believed Documentation was a set of activities analogous to cataloging and reference service (library activities) whereas Bibliography, endowed with greater scientificity than Documentation, was focused on bibliographic production and its role in social communication, also supported by Library Science. We conclude that Otlet's emancipatory speech made way for the establishment of a document science (Documentation), while Ranganathan's speech gave scientific authority to Library Science in order to deal with both Documentation and Bibliography.
\end{abstract}

Keywords: Bibliography. Documentation. Otlet. Ranganathan. Library Science.

InCID: R. Ci. Inf. e Doc., Ribeirão Preto, v. 12, n. 2, p. 4-31, set. 2021./fev. 2022.

DOI: 10.11606/issn.2178-2075.v12i2p4-31 


\section{Considerações iniciais}

Bibliografia e Documentação são saberes teóricos e práticos cujas dialogicidades no universo documental/informacional são abordadas de diferentes maneiras pela literatura, especialmente quando vistas sob as perspectivas de diferentes pensadores. Enquanto a primeira parece ocupar espaço central dentro da longa tradição biblioteconômica, a segunda parece ter traçado um movimento emancipatório da própria Biblioteconomia na virada do século XIX para o XX.

Recorrendo à literatura, percebemos que Bibliografia e Documentação, embora se trate de áreas distintas, são igualmente compreendidas ora como atividades voltadas aos livros e documentos, ora como disciplinas preocupadas com os livros e documentos. Há, portanto, certa imprecisão relativa à natureza dessas áreas que por vezes provocam inquietações a estudiosos do campo informacional. Por outro lado, a polissemia relativa aos conceitos de Bibliografia e Documentação proporciona terreno fértil para se trabalhar as complexidades que envolvem ambas as áreas.

Neste estudo, centramos esforços para compreender as perspectivas que Paul Otlet (1868-1944) e Shiyali R. Ranganathan (1892-1972) tinham a respeito da Bibliografia e da Documentação, de modo a refletir sobre a tensão epistemológica existente entre esses dois importantes nomes da Biblioteconomia e da Ciência da Informação no que se refere ao universo bibliográfico e documental. Longe de tentar esgotar a compreensão que ambos os autores tinham sobre Bibliografia e Documentação, acreditamos ser relevante colocar em destaque os entendimentos que ambos imprimiram a esse respeito, de modo que possamos, de alguma forma, contribuir para o debate epistemológico que envolve a Bibliografia e a Documentação.

Importante frisar que não confrontamos aqui Otlet e Ranganathan com o simples desejo de enunciar uma rivalidade teórica entre dois repercutidos autores do campo da informação, mesmo porque, em outros espaços epistemológicos, como o da organização do conhecimento, por exemplo, Otlet e Ranganathan estabeleceram muito mais convergências do que divergências, como pode ser observado em Sales e Guimarães (2017) e Sales et al. (2019). Nosso propósito aqui é colocar em relevo duas perspectivas contemporâneas distintas sobre Bibliografia e Documentação, surgidas no século XX. 
Assim, o objetivo deste estudo foi investigar a compreensão que Otlet e Ranganathan tinham a respeito da Bibliografia e da Documentação e como ambos as relacionaram com a Biblioteconomia.

Para tanto, adotamos como abordagem metodológica uma análise comparativa entre as obras Traité de Documentation (1934), de Otlet, e os livros Social Bibliography or Phisical Bibliography for Librarians (1952) e Documentation: Genesis and Development (1973), de Ranganathan. O Traité de Otlet é a obra de maturidade do autor, onde o saber teórico e prático da Bibliografia e da Documentação foi devidamente sistematizado. Os citados livros de Ranganathan foram as obras em que o autor abordou pontualmente suas compreensões a respeito da Bibliografia e da Documentação. O cotejamento das citadas fontes foi realizado de forma discursiva e tomou como parâmetros as definições que os autores deram para Bibliografia e Documentação, bem como suas relações com a Biblioteconomia. Portanto, trata-se de um exercício de reflexão teórica que, por meio da análise comparativa, buscou dissertar a respeito das tensões epistemológicas existentes nos estudos de Bibliografia e Documentação, destacando as divergências existentes entre os discursos de Otlet e Ranganathan.

Do ponto de vista estrutural, este artigo está sequencialmente composto por esta Introdução e por seções que versam respectivamente sobre: Bibliografia, Documentação, tensões epistemológicas entre Otlet e Ranganathan, comparação dos discursos de ambos os autores, algumas considerações finais e referências bibliográficas.

\section{Uma visita à bibliografia}

A palavra "bibliografia" diz respeito a prática de (des)escrever (graphein) sobre livros (biblion). A bibliografia enquanto prática concerne ao processo de representação documentária, que visa sintetizar um determinado conteúdo relativa à uma obra de a fim de criar um intermediário que viabilize a sua localização posteriormente. O termo bibliografia também pode se referir ao resultado desse processo de representação, o produto em si, o conjunto de referências bibliográficas normalmente em formato de lista, ordenado segundo uma lógica cronológica, alfabética ou por assunto. Ainda, Bibliografia pode designar uma disciplina de estudo (ARAÚJO, 2015; LARA, 2018).

A prática de guardar, acessar e utilizar os registros de conhecimento é quase tão antiga quanto a escrita. Um dos primeiros nomes ligados ao trabalho de inventariar um conjunto de 
obras de uma coleção é o de Calímaco (310 a.C. - 240 a.C.), que desenvolveu uma espécie de catálogo da Biblioteca de Alexandria, os chamados pinakes. Uma espécie de tabela que registrava o nome dos autores gregos com dados biográficos, como nome dos pais e local de nascimento (MANGUEL, 2006; SORDET, 2019). Além disso, o bibliotecário estabeleceu categorias de assunto que provavelmente espelhava a distribuição física das obras na biblioteca. Não há consenso sobre quais eram tais categorias, mas Manguel (2006) admite ao menos oito classes: teatro, poesia, legislação, medicina, história, filosofia e miscelânea. De toda forma, os pinakes estavam ligados a uma única instituição, e não há diversas.

Cassiodoro (490 - 581) foi o responsável pela criação de uma das bibliografias de maior destaque da Idade Média, pois compilou as obras mais fundamentais à formação dos monges. Institutiones divinarum et saecularium litterarum foi mais que uma lista de documentos, pois orientou a constituição de bibliotecas e as práticas de leitura da época (CRIPPA, 2015).

Já no século XVI, com a prensa móvel cada vez mais disseminada na Europa, a necessidade de compilar referências foi ratificada e o meio viável de identificar, localizar e acessar às obras. Com isso, surgem cada vez mais bibliografias universais, um remédio a desordem crescente impulsionada pela multiplicação de livros impressos (WOLEDGE, 1983).

\footnotetext{
A tecnologia da impressão promoveu uma primeira modificação na atividade da organização e preservação de documentos, uma vez que, aos poucos, foi retirada da biblioteca a tarefa de reprodução de manuscritos realizada pelos copistas, que passou a ser feita em oficinas especializadas. Apesar do crescente destaque social vivido pela biblioteca a partir de então, pode-se dizer que o trabalhador da biblioteca perdeu certa responsabilidade, cumplicidade e envolvimento com os documentos, já que não realizava mais a reprodução dos mesmos e a compreensão e organização dos conteúdos que lhe é decorrente. Aos poucos, tanto a biblioteca quanto o "bibliotecário" de então se distanciaram dos processos de organização, mas ganharam maior visibilidade pública e social (ORTEGA, 2004, n.p).
}

Neste contexto, a tarefa de representação de livros se tornou uma atividade especificamente desenvolvida por bibliógrafos, que eram, normalmente, estudiosos de diversos saberes, não necessariamente vinculados ao trabalho de bibliotecário.

Johannes Trithemius (1462-1516) criou, em 1494, uma listagem de autores e títulos compreendidos na civilização cristã, intitulada Liber de scriptoribus ecclesiasticis. O bibliógrafo suíço Conrad Gesner (1516 - 1565) publicou, entre 1545 e 1555, a obra Bibliotheca Universalis, composta por quatro partes que apresentam informações bibliográficas relativas a 
mais de cinco mil autores, expressas em latim, grego e hebraico, com extratos e resumos das obras referenciadas.

A Bibliotheca de Gesner é considerada o marco inicial da Bibliografia moderna. De acordo com Araújo (2015, p. 135), “Em Bibliotheca é possível identificarmos não só o tratamento descritivo/ semântico dado aos documentos, mas também justamente sua dimensão mediadora e memorial". Burke (2002) aponta para o surgimento sucessivo até o século XVIII de bibliografias específicas, bibliografias nacionais, organizadas por assuntos ou campos de conhecimento, contendo as vezes orientações sobre como formar uma coleção, como selecionar uma obra para ler que, de certa forma, eram guias para o mundo livresco.

A Bibliografia, enquanto campo de estudo, ganhou cientificidade a partir dos séculos XIX e XX, sobretudo com Sir Walter Wilson Greg (1875-1959), Alfred William Pollard (1859-1944) e Ronald B. McKerrow (1872-1940), três pesquisadores ingleses que buscaram desenvolver uma ciência dos livros, a Bibliografia, conforme aponta Roberson (2001).

Nesse sentido, observasse na literatura que os estudos de Bibliografia se dividem em duas partes. Embora não haja consenso sobre o nome de cada uma dessas partes, Roberson (2001) as distingue sob duas abordagens: a enumerativa/sistemática e a analítica/crítica. A bibliografia enumerativa ou sistemática é aquela "that lists books systematically. This could be a listing of every book an author has written or it could be a listing of every book located in a specific collection" (ROBERSON, 2001, p. 5). Já a bibliografia crítica ou analítica é centrada na "identification and description of a book and the context in which it was written. In other words, it is the analysis of the process that is necessary to create the book" (ROBERSON, 2001, p. 5). McKenzie (2018, p. 24) identifica que entre as duas abordagens há na verdade uma sucessão paradigmática: “da maior parte daqueles que reconheço como bibliógrafos não podem mais ser satisfeito apenas pela descrição, nem mesmo pela edição, mas sim pelo estudo histórico da feitura e do uso de livros e outros documentos". Já Araújo (2015) prefere designar as diferentes abordagens como a "esfera teórico-aplicada" e a "esfera material" das bibliografias. A primeira está relacionada às práticas de descrição e representação dos livros para sua guarda, localização e acesso, ao passo que a segunda diz respeito aos estudos da forma do livro e de sua influência na apropriação das obras.

A Bibliografia, enquanto ciência, teve um importante impulso para sua institucionalização com a fundação em Londres da Bibliographical Society (1892), destinada 
ao estudo e promoção da área, com publicações ainda realizadas no periódico The Library. Outro periódico de destaque é o Studies in Bibliography, iniciado em 1948 por Fredson Bowers.

De acordo com Ortega (2004), após as obras de Johannes Trithemius e Conrad Gesner, foram publicados diversos catálogos de bibliotecas na Europa e essas produções constituíram as bases da Documentação. Ainda, cabe destacar que a perspectiva pós-custodial (SILVA; RIBEIRO, 2002) sobre os acervos bibliográficos e documentais, que centra sua atenção mais à informação que no registro, encontra seus fundamentos também na Bibliografia, que não se limitava à compilação de coleções institucionais, cartografava obras espalhadas pelas bibliotecas.

\section{O percurso à documentação}

De acordo com Ortega (2004), a produção de periódicos científicos atingiu um pico na metade do século XIX, obrigando bibliotecários e bibliógrafos a se debruçarem sobre esse tipo específico de material. Neste contexto, o esforço principal estava voltado ao tratamento dos assuntos dos artigos. No entanto, dada a diversidade dos temas, a quantidade crescente de documentos e as especificidades das técnicas biblioteconômicas, que não eram satisfatórias numa simples sobreposição aos jornais científicos, o trabalho de tratamento de assuntos dos artigos ficou a cargo de grupos de bibliógrafos focados nos desafios desse tipo de recurso. Os bibliógrafos que compunham esses grupos ficaram conhecidos como documentalistas, "esse segmento foi recolhido e desenvolvido pelo crescente grupo de documentalistas, deixando o bibliotecário de ter como atribuição o tratamento de parte da literatura e a biblioteca reduzindose a sua antiga função de custódia de documentos (ORTEGA, 2004, n.p)”.

Para Ortega (2004), durante o século XIX, os instrumentos, as técnicas e a prática da Documentação eram marcadamente semelhantes às atividades desempenhadas pelos bibliotecários. Porém, havia ainda a necessidade de aprofundar a análise dos assuntos dos documentos, o que levou à produção de um novo ferramental à essa disciplina, afastando-a, também por divergências políticas e profissionais, da Biblioteconomia que, por sua vez, centrava esforços mais na dimensão educacional da biblioteca pública que nas tarefas bibliográficas e catalográficas. Nesse cenário, associações profissionais de documentalistas surgiram em razão ou de conflitos internos de associações de bibliotecários ou, também, como forma de concorrer com estas últimas em diversos países. 
A Documentação teve na Bibliografia seu princípio norteador, mas adquiriu nomenclatura e corpus próprio a partir das primeiras décadas do século $\mathrm{XX}$, notadamente com as contribuições de Paul Otlet e Henri La Fontaine. A área da Documentação foi marcada teoricamente pela publicação do Traité de Documentation (1934), obra que sistematizou a prática que era aplicada e aprimorada há pelo menos 40 anos. Destaca-se que mesmo antes da publicação do Traité o termo "documentação" já era empregado para designar atividades e produções do grupo de documentalistas que se organizava em torno principalmente de Otlet (ORTEGA, 2004).

Um dos principais projetos realizados no universo da Documentação foi a concepção do Repertório Bibliográfico Universal (RBU), um catálogo formado por fichas com informações bibliográficas que procurava reunir toda a produção intelectual humana, cuja finalidade era o acesso universal ao conhecimento registrado, capaz de atualizar um especialista sobre os conhecimentos mais recentes desenvolvidos em sua área de pesquisa. Assim, iniciou-se um processo com pretensões mundiais, de coleta, organização e disseminação de informações documentais.

Esse movimento internacional começou com a I Conferência Internacional de Bibliografia, realizado em 1895, na qual foi fundado o Instituto Internacional de Bibliografia (IIB), com sede em Bruxelas, que mais tarde viria a se chamar Instituto Internacional de Documentação (IID), em 1931, Federação Internacional de Documentação (FID), em 1938, e Federação Internacional de Informação e Documentação, a partir de 1986 (RAYWARD, 1975).

Uma das missões do IIB foi congregar colaboradores documentalistas em torno da organização e desenvolvimento de um instrumento de análise de assunto e de classificação mais adequada que a já conhecida e popular Classificação Decimal de Dewey (CDD). Com o crescimento do RBU, foi inevitável a necessidade de uma classificação mais específica que a CDD e, por isso, o IIB lançou um instrumento próprio, em 1904, que inicialmente foi denominada de Classificação Decimal de Bruxelas, mas que três anos mais tarde passou a ser conhecida como Classificação Decimal Universal (CDU). Sua vantagem era a possibilidade de especificar os detalhes de um documento.

O já mencionado Traité de Documentation: le livre sur le livre, théorie et pratique foi uma obra que trouxe o acúmulo de anos de trabalho. Seu intuito era fundamentar uma nova e ampla área científica, a Bibliologia, na qual a Documentação portaria grande parte dos métodos 
e operações intelectuais. O papel fundamental da Documentação era o de atuar no mundo da ciência e da cultura, de forma a coletar registros de informação detalhados e padronizados, visando sua sistematização e disponibilização a partir de um centro que coordenasse uma ampla rede que, por sua vez, serviria como a interface de interação de possíveis usuários com esse sistema de informação (OTLET, 2018).

A Documentação para Otlet era o trabalho sobre o registro documental, fosse ele um livro, um artigo, uma fotografia, uma peça histórica etc. Segundo o pensador belga, o que definia o documento era mais a sua "função" documental que sua "forma". Por esta razão, a noção de documento, ou livro, deveria ser tomada em um sentido amplo. Assim, a Documentação, enquanto série de operações que atuam sobre o documento, dá-se na cadeia de desenvolvimento desse último, passando por diferentes instituições e ofícios. "A Documentação acompanha o documento desde o instante em que ele surge da pena do autor até o momento em que impressiona o cérebro do leitor" (OTLET, 1937, n. p).

De acordo com Otlet (1937, n. p)

O homem, alternativamente, retira idéias da realidade ou introduz idéias na realidade;
entre a realidade e a idéia intervém, cada vez mais, os documentos que, por sua vez,
servem à elaboração de novos documentos. O conjunto dos documentos existentes
deve ser constantemente caldeado e macerado, submetido às operações de uma
'química', mais exatamente, de uma 'metalurgia documental' (pois que se trata da
extração de elementos, da refinação, de liga e de soldagem). Da mesma maneira que
se deve separar de sua ganga o metal puro, assim separa-se a verdade, original e tida
por dita uma vez, da massa de erros e de repetições.

Nesse sentido, a Documentação é entendida como um conjunto de esforços no tratamento do livro, que deveria dar-se em cooperação internacional, a fim de tornar os processos de indexação e recuperação da informação mais precisos. A partir do RBU, a intenção era criar um "livro universal" que viabilizasse um centro de tratamento e acesso informacional, calcado nas práticas documentais (OTLET, 1990, 1937, 2018). Para tanto, além das técnicas tradicionalmente aplicadas por bibliógrafos e bibliotecários, seria necessário o empenho de documentalistas no desenvolvimento de novos ferramentais voltados as abstrações e sínteses dos assuntos dos diversos documentos (OTLET, 1990), que garantissem a fluidez da informação e a sua mobilidade entre seus suportes originais e os produtos documentários, impulsionando a diversificação de fontes secundárias e terciárias.

A intenção política de Otlet reflete também em seu discurso teórico-prático sobre a Documentação, seja na sua articulação de redes de colaboradores nas tarefas documentais, seja 
na sua concepção epistemológica sobre as noções de Bibliografia e Documentação. Note-se o uso dos termos bibliógrafos, bibliotecários e documentalistas, marcando a distinção de funções desempenhadas por campos distintos.

Se por um lado a Documentação se firmava e se institucionalizava como uma nova disciplina científica, sob uma tradição francófona, alavancada pelo discurso seminal de Otlet em seu Traité, por outro, havia uma perspectiva distinta que preferia abordar a Documentação não necessariamente como uma ciência, mas sim como uma prática biblioteconômica, conforme argumentado por Ranganathan (1973), que, embora raramente associado às discussões epistemológicas relativas à Documentação e à Bibliografia, teceu também seu entendimento a respeito deste assunto. Entretanto, a perspectiva ranganathiana partiria de outro contexto disciplinar.

Shiyali Ramamrita Ranganathan (1892-1972), nascido na cidade de Shiyali, estado de Madras, Índia, teve seu nome impresso nos estudos voltados aos livros e às bibliotecas devido suas inúmeras contribuições teóricas à Biblioteconomia, de especial maneira aos assuntos relativos à prática profissional, à classificação bibliográfica e à organização do conhecimento. Autor de dezenas de livros e artigos que tratavam das mais variadas funções biblioteconômicas, tais como catalogação, indexação, administração de bibliotecas e estudos de usuários, o matemático e bibliotecário indiano despontou efetivamente como nome central da Biblioteconomia do século XX a partir da publicação da obra The Five Laws of Library Science, em 1931, motivo pelo qual Ranganathan logrou grande repercussão internacional ao sintetizar a relação livro-biblioteca-bibliotecário-usuário, definindo, assim, diretrizes fundamentais para o desenvolvimento de uma Biblioteconomia mais dinâmica. Tal obra se tornaria uma espécie de livro obrigatório para os estudos biblioteconômicos a partir de então.

Se a definição das cinco leis foi a grande contribuição generalista de Ranganathan para a Biblioteconomia, é seguro afirmar que sua contribuição mais especializada se deu no ramo das classificações bibliográficas, tema que despertou especial atenção de Ranganathan após sua rápida formação biblioteconômica (1924-1925) no University College de Londres. No entanto, somente uma década depois começariam a surgir suas obras sobre as classificações: Colon Classification (1933), Classified Catalogue Code (1934), Prolegomena to Library Classification (1937), Classification: Fundamental and Procedure (1944), Elements of Library Classification (1945); Classification and International Documentation (1948), Classification 
and Communication (1951) e Headings and Canons (1955) (PIEDADE, 1983; YOGESHWAR, 2001).

Sua dedicação às classificações de bibliotecas foi além da concepção de uma nova classificação (Colon Classification), culminou, de fato, no desenvolvimento de uma teoria voltada à construção de sistemas de classificação (Teoria da Classificação Facetada) e no aprimoramento de um método para tal construção (método analítico-sintético). Ranganathan foi o primeiro dentre os classificacionistas de bibliotecas a se preocupar em deixar seu legado teórico por meio de inúmeras publicações que objetivavam instrumentalizar os bibliotecários a respeito de seu sistema e de sua teoria. No âmbito das classificações de bibliotecas, a Teoria da Classificação Facetada despontou como um novo modo de pensar e fazer. Mais que um instrumento de classificação, tratava-se de um novo modo de classificar (SALES, 2016).

No entanto, conforme afirmado anteriormente, Ranganathan não se deteve apenas às discussões classificatórias e instrumentais, mas transitou também nos mais variados temas que envolviam o universo das bibliotecas, dentre eles, a Bibliografia e a Documentação, vistas, via de regra, como práticas exercidas por profissionais de bibliotecas. Na obra intitulada Social Bibliography or Phisical Bibliography for Librarians, publicada em 1952, tomamos contato com o pensamento que Ranganathan tinha a respeito da Bibliografia. Em outra obra, intitulada Documentation: Genesis and Development, publicada postumamente em 1973, temos a noção da compreensão que Ranganathan tinha a respeito da Documentação, marcadamente concebida a partir do pensamento de um bibliotecário, não de um documentalista. As diferentes perspectivas a respeito da Bibliografia e da Documentação nas visões de Otlet e Ranganathan são apresentadas nas próximas seções.

\section{Tensões epistemológicas nos estudos documentais: Otlet e Ranganathan}

Ao estagiar, ainda jovem, no escritório de advocacia de Edmond Picard, jurista envolvido no movimento socialista belga e responsável pela publicação de bibliografias na área do Direito, Otlet se aproximou do trabalho de bibliógrafo e desenvolveu as bases para seu pensamento sobre os problemas documentários, além de conviver profissionalmente com Henri La Fontaine, seu grande parceiro nas ações documentais.

Nesse período, Otlet dedicou-se aos problemas bibliográficos tendo em vista o desenvolvimento dos conhecimentos científicos. As primeiras bibliografias desenvolvidas por 
Otlet foram nas áreas do Direito, Psicologia e Sociologia (RAYWARD, 1975). Nos dois anos que antecederam a criação do IIB, Otlet e La Fontaine, ainda ligados ao escritório de Picard, fundaram uma seção neste, denominada International Institute of Sociological Bibliography (IISB), na qual procuravam a cooperação internacional para a produção de fichas com dados bibliográficos. Notadamente, essa experiência substanciou a constituição do IIB.

Entre 1894 e 1895, Otlet e La Fontaine publicaram quatro bibliográfias: L'Office International de Bibliographie Sociologique: économie sociale, législation, statistique; Sommaire Méthodique des Traités, Monographs et Revues de Droit; Sommaire Méthodique des Traités e Monographies et Revues de Sociologie (RAYWARD, 1975). Nesse contexto, já eram percebidas as limitações dos sistemas de organização das bibliografias, que arranjavam as referências em ordem alfabética de autor e assunto.

Otlet percebeu na Classificação Decimal de Dewey (CDD), que se encontrava já em sua quinta edição, um instrumental com potencial à sistematização do repertório em desenvolvimento no IIB. A CDD propunha uma organização de assuntos pautada em classes decimais abstratas, sob uma forma hierarquica, viabilizando a ampliação dos acervos bibliográficos sem grandes prejuízos às ordenações física e conceitual do sistema. A lógica presente na CDD facilitaria o manejo dos dados bibliográficos no âmbito internacional, uma vez que a mesma se pretendia universal e se valia de uma linguagem também universal, a linguagem numérica. Além disso, o uso da CDD permitiria que o enfoque da atividade dos bibliógrafos recaísse sobre os conteúdos dos documentos, deixando as questões formais à um segundo plano de importância, fato que não implicaria, na época, em obstáculo à internacionalização dos trabalhos bibliográficos. Assim, ainda no final de 1985, o IIB publicou Sociologie et Droit. Sozialwissenschaft und Recht. Sociology and Law. Sommaire méthodique des traités et des revues, drésse conformement à la Classification Decimale.

A concretização das mencionadas bibliografias foi um passo importante para a concepção do RBU, que pretendia apresentar fichas com dados bibliográficos relativos à produção documental mundial, sobre todos os assuntos, com o intuito de permitir o acesso a esses registros, tornando possível inclusive a identificação do local onde os documentos se encontravam.

Os traços utópicos dos projetos de Otlet perseguiam notadamente a mundialização das atividades atinentes à organização e à recuperação da informação, sem, contudo, deixar de lado 
o pragmatismo necessário para a institucionalização de um, ainda novo, fazer científico que, por sua vez, mudaria de forma definitiva o status da Bibliografia e, posteriormente, daria contornos à criação da Documentação. Em outras palavras, era flagrante nas atuações de Otlet a intencionalidade de instaurar uma nova ciência, que, diga-se de passagem, já ganhara forças a partir da Primeira Conferência Internacional de 1895, na qual foram definidos a construção do repertório universal (RBU), o estabelecimento do instituto internacional (IIB) e a criação do Escritório Internacional de Bibliografia (SALES; MURGUIA, 2015). Desde a fundação do IIB, o projeto cresceu exponencialmente tanto em produção de fichas bibliográficas, quanto em número de países e organizações aderentes, tendo como um dos marcos desse trajeto o estande na Exposição Universal de Paris de 1900, no qual foram realizadas demonstrações de descrição e recuperação de informação para um vasto público (RAYWARD, 1975).

A equipe do IIB utilizou a CDD com relativo sucesso, contudo, com o aprofundamento do trabalho realizado no RBU, tal instrumento revelou-se insuficiente. Dewey havia desenvolvido sua classificação pensando especificamente na organização de livros em estantes, como uma alternativa aos arranjos alfabéticos e cronológicos comuns até meados do século XIX. Os trabalhos realizados no IIB, especialmente relativos ao RBU, não se restringiam aos materiais bibliográficos, tampouco às bibliotecas, mas adentravam também nos arquivos, museus e organizações empresariais e similares. Com isso, foram sugeridas, pelo próprio Otlet, algumas alterações à CDD, o que não foi imediatamente acolhido por Dewey, que mantinha seus olhares nos acervos de biblioteca. Assim, o IIB publicou entre 1904 e 1907 o Manuel du Répertoire de Bibliographie Universelle que, em 1927 e 1933, ganharia uma segunda versão, ampliada e atualizada, então denominada Classification Décimale Universelle (Classificação Decimal Universal - CDU) (RAYWARD, 1975).

No âmbito do IIB, Otlet foi construindo uma concepção própria sobre as Ciências Bibliológicas, voltada para os registros documentais, para os conhecimentos e informações contidas nos registros documentais, bem como para as representações e os processos decorrentes da organização, recuperação e comunicação de tais registros. Para Otlet (2018), os produtores de documentos, de livros, lidavam com fragmentos da realidade. Nesse sentido, a reunião desses documentos, mais especificamente, de seus registros, permitiria a constituição de um livro único e universal, um livro total, que impulsionaria o desenvolvimento científico, social e cultural. Por isso, o projeto de Otlet não era apenas técnico, mas pretendia uma dimensão ética, promotora da paz mundial (RAYWARD, 1975). 
Todavia, para isso, era preciso direcionar o foco a o tratamento dos documentos, de modo a classificá-los e torná-los acessíveis. Nesse sentido, Otlet entendia que a mesma operação do método científico deveria ser aplicada no fazer documental, a saber: um processo de análise e síntese (OTLET, 2018). Nesse contexto, foi publicado o Traité de Documentation.

O intuito do Traité foi teorizar sobre todo o processo de criação e circulação dos documentos, com a finalidade de viabilizar o acesso da informação, por meio de técnicas e métodos que ultrapassariam os da Biblioteconomia (OTLET, 2018). Otlet chegou a sugerir que num futuro próximo a informação poder-se-ia acessada por meio de recursos tecnológicos que integrariam as então recentes ferramentas desenvolvidas, tais como rádio, televisão, cinema e disco. Vislumbrava um mundo em que a informação estaria facilmente disponível e seria base de uma sociedade por vir, a qual não imergiria sem uma ciência para pensar o documento e uma prática para garantir seu acesso. Esta pesquisa buscou no Traité a concepção francófona de Bibliografia e Documentação, a fim de evidenciar convergências e divergências com o discurso ranganathiniano.

Na obra Social Bibliography or Phisical Bibliography for Librarians, Ranganathan (1952) aborda a Bibliografia sob o ponto de vista do domínio da Comunicação, dando especial atenção aos aspectos sociais que envolvem o fazer bibliográfico, notadamente aqueles que dizem respeito à vida material e à função social do livro, viabilizadores da comunicação humana para além dos limites do tempo e do espaço. A polissemia que recaía sobre o termo Bibliografia promovia, segundo Ranganathan (1952), um jogo de homônimos e sinônimos que tornava dispersa a compreensão a respeito de todos os conceitos possíveis para a Bibliografia. No entanto, para Ranganathan, todos os conceitos recaiam especificamente no campo da Comunicação.

\footnotetext{
Communication is necessary for their satisfactory and efficient living in all the five planes - physical, vital, emotional, intellectual and spiritual planes. Men in the highest reaches of the spiritual plane communicate by radiation, direct thought-transfer perhaps, quite unmediated by aid of any sort - sans gestures, symbols, sounds, words, writing, printing or books (RANGANATHAN, 1952, p. 20)
}

O livro seria uma espécie de entidade física de comunicação que transcendia os limites de tempo e espaço, diferentemente dos outros meios de comunicação, como gestos, símbolos, sons e imagens, limitados no imediatismo do tempo e do espaço.

Men in the normal levels of mental existence communicate with the aid of gestures, symbols, sounds, words, and written and printed books. The first four media of communication limit the range of time and space that can be covered. In time it is 
momentary and in space it is limited by visibility or audibility. The last two media make communication transcend the limitations of time and space. These media may be said to transform the thought to be communicated into physical entities called Books, and make it fit for transport across space and through time (RANGANATHAN, 1952, p. 20)

A Bibliografia, na perspectiva ranganathiana, teria a ver com o modo de comunicação inerente à sociedade humana, na medida em que dizia respeito ao livro, manuscrito ou impresso, ou seja, um meio físico com uma função social de comunicação.

Even within the sphere of printed medium, Bibliography is a term which has had and still has several meanings. First it denoted the physical process of writing or transcribing books, as distinct from the intellectual or intuitive process of composing books i.e., creating or building up their thought-content and clothing it in a language or any other subtle medium as a first step in communication. It was later made to denote also composition of books (RANGANATHAN, 1952, p. 21).

Observamos que, alicerçado por este viés comunicacional, Ranganathan foi além da abordagem meramente descritiva das bibliografias (que tinha por função descrever formalmente os livros) e centrou atenção também nos aspectos atinentes à produção dos livros. "Ebert, the German bibliographer, extended the definition to 'In the greatest sense, the science that deals with the literary productions'. This led to the definition 'the science of books'. This definition passes the problem on to the term 'Book"'. (Idem, p. 21).

Aderente à ideia de que a Bibliografia deveria ser abordada como a ciência dos livros, atrelada, por sua vez, ao campo da Comunicação, Ranganathan (1952) desenvolveu seu discurso sobre Bibliografia dando total primazia ao objeto livro. Reconhecendo que o termo livro podia trazer à mente inúmeras ideias, variando de pessoa para pessoa e de contexto para contexto, Ranganathan categorizou os mais variados tipos de bibliografias com base nos diferentes olhares e funções que um livro poderia cumprir: bibliografia de assunto, que consistia numa lista de micro ou macro pensamentos incorporados nos livros ou periódicos sobre assuntos especializados (vinculado ao trabalho de documentação, como veremos mais adiante); bibliografia linguística, uma lista de materiais de leitura em um idioma específico e; bibliografia expositiva, lista de livros que estavam na forma de ensaios. Além de se referir às listas de obras, esses termos específicos para as bibliografias acima citadas podiam denotar também o trabalho de preparar qualquer um desses tipos de listas. Ou seja, Bibliografia seria tanto a lista de obras (produto) quanto a elaboração das listas (processo).

O principal objetivo dessas bibliografias mencionadas acima era disponibilizar uma lista de livros existentes em uma biblioteca ou em um determinado campo de estudo, fosse sobre um 
período de tempo definido, ou sobre um assunto específico, ou sobre um determinado idioma ou, ainda, sobre uma determinada forma de exposição. Por esta razão, Ranganathan (1952) afirmava se tratar de bibliografias de existência.

Outros tipos de bibliografias apresentadas por Ranganathan (1952) são: bibliografia física, que se preocupa apenas com o corpo físico do livro, mas lida também com o processo de produção do livro, tais como o papel, a impressão, as ilustrações, as partes do livro, outras formas físicas nas quais os livros estariam sendo reproduzidos etc.; bibliografia analítica, baseada na análise meticulosa de todas as características físicas de um livro e; bibliografia histórica, que seriam várias bibliografias agrupadas para apresentarem uma história de impressão e produção de livros. Todos esses tipos de bibliografias Ranganathan dizia pertencer a esfera da aristocracia acadêmica, que transitaram pelos primeiros quatro séculos da era de Gutenberg, e que foram pelo próprio Ranganathan denominadas genericamente como PalaeoBibliography (1952, p. 30).

Avançando um pouco mais na função comunicacional da produção bibliográfica, Ranganathan afirmava ser necessário deixar para trás a esfera aristocrática acadêmica e trabalhar em prol de uma abordagem mais voltada à sociedade em geral, promovendo uma esfera de Democracy in Education, dando vez à chamada Bibliografia Social. Nessa esfera, os livros deveriam se tornar ferramentas eficazes de auto-educação e entretenimento, tornando-se mais acessíveis e atrativos para o homem comum. Este movimento de levar o livro para a autoeducação e entretenimento da massa foi chamado por Ranganathan de Bibliografia Social. Para tanto, seria necessário que bibliotecários, atentos ao seu papel na economia social, implementassem as Cinco Leis da Biblioteconomia para se pensar a produção bibliográfica. Nesta perspectiva ranganathiana, produção bibliográfica equivale ao livro como produto físico e apenas como recipiente do pensamento abstrato.

Implementando as cinco leis à produção bibliográfica, Ranganathan acreditava ser possível tornar o livro mais interessante e acessível às massas, dissolvendo as relações fortemente marcadas pelos privilégios da aristocracia acadêmica. E esta função deveria ser levada a cabo pelos bibliotecários.

Ranganathan (1952) relacionou da seguinte maneira a Bibliografia Social com as Cinco Leis da Biblioteconomia:

- Primeira Lei - Livros são para Uso (material do mistério) 
Foco no material a ser usado como base do livro, atenção especial para o manuseio.

- Segunda Lei - Para cada Leitor, seu Livro (arte milagrosa)

Foco no interior do livro: (1) modo de registro, (2) disposição das linhas, (3) forma das letras, (4) tamanho das letras, (5) ilustrações, (6) padronização, (7) tamanho dos livros e (8) encadernação.

- Terceira Lei - Para cada Livro, seu Leitor (estética)

Apelo aos sentidos e ao que agrada aos olhos. Apelo estético para aumentar o número de pessoas que serão atraídas pela aparência estética do exterior e interior do livro.

- Quarta Lei - Poupe o tempo do leitor (layout)

Não é apenas o tempo objetivo do leitor que deve ser poupado, mas também o tempo subjetivo. Economizar o tempo subjetivo é equivalente a economizar o ritmo, a energia do leitor. Foco nas informações auxiliares: (1) título na lombada da encadernação, (2) informação de contracapa, (3) sumário, (4) sinopse; (5) índice, (6) introdução etc.

- Quinta Lei - A Biblioteca é um organismo em crescimento (novas encarnações)

Foco nas possibilidades de redução de tamanhos de materiais (microformas) e ocupação de espaços (descartes e seleções).

Com a aplicação das cinco leis na produção bibliográfica, nos moldes descritos acima, seria, segundo Ranganathan, possível tornar o livro e a biblioteca mais interessantes ao cidadão comum, promovendo, assim, a Bibliografia Social.

Observamos que toda a concepção de Bibliografia de Ranganathan é construída a partir do campo da Biblioteconomia, assim como a concepção de Documentação, conforme segue.

Para Ranganathan (1973), Documentação era um termo genérico adotado para denotar duas, e somente duas, atividades especializadas: a) o trabalho de documentação e b) o serviço de documentação.

Segundo o bibliotecário indiano, o trabalho de documentação se relacionava diretamente com o já conhecido trabalho de catalogação. No entanto, enquanto a catalogação se ocupava com a elaboração de 'listas bibliográficas', ou melhor, catálogos que descreviam informações bibliográficas sobre livros, a Documentação se ocuparia com a elaboração de 
'listas de documentação', ou seja, listas que descreviam informações bibliográficas sobre micro documentos ou partes de documentos, como capítulos de livros, artigos de revista etc., podendo, para isso, lançar mão de elaboração de resumos ou não. As listas de documentação estariam voltadas a leitores especialistas (RANGANATHAN, 1973).

O serviço de documentação, por sua vez, estaria diretamente ligado ao já conhecido serviço de referência, cuja ênfase estaria, assim como no trabalho de documentação, voltada para os micro documentos com vistas a atender demandas especializadas de informações (Idem). Nesse sentido, o autor foi enfático ao afirmar que, assim como o trabalho de documentação seria o trabalho de catalogação desenvolvido com maior intensidade (especialização), o serviço de documentação seria também o serviço de referência levado a cabo com preocupações mais especializadas. Em outras palavras, é seguro afirmar que para Ranganathan (1973), a Documentação era um conjunto de atividades especializadas já executadas por profissionais de bibliotecas, mas, que dada a crescente demanda especializada por parte dos usuários, exigiam maior especificidade.

Temos, neste contexto ranganathiano, uma noção de Documentação como mera atividade especializada executada por bibliotecários a serviço de leitores especialistas que, por sua vez, demandavam documentos também especializados. Assim, Ranganathan (1973) associou atividades já desempenhadas pela Biblioteconomia (catalogação e serviço de referência) e acrescentou as novas exigências de especialização que diziam respeito tanto aos documentos (micro documentos) quanto aos usuários (especialistas de diversas áreas de conhecimento e atividades profissionais). Para o autor, as atividades de Documentação eram inseparáveis das atividades das bibliotecas. Em diversas passagens de seu livro, Ranganathan (1973) afirma que a Documentação era uma função essencial dos bibliotecários.

\section{O discurso de Otlet, o discurso de Ranganathan}

Bibliografia, Documentação e Biblioteconomia são disciplinas próprias, cada qual com sua história, corpus e função. Todavia, há uma interseção teórico-prática entre essas, um liame impreciso no qual ocorre um trânsito que movimenta o próprio devir das disciplinas.

Os discursos de Otlet e Ranganathan interpelam o agir e o pensar contemporâneo dessas disciplinas e da correlata Ciência da Informação. Se Ranganathan foi nome central na Biblioteconomia do século XX, por entender a relevância desta no mundo da informação, Otlet 
apontou para uma necessidade de superação das técnicas biblioteconômicas como condição para solver problemas informacionais no alvorecer do século XX.

Nesse sentido, Otlet e Ranganathan discursaram sobre Bibliografia, Documentação e Biblioteconomia, mas sob horizontes distintos. O advogado belga tinha um projeto para estruturar uma rede de organizações, centralizadas no IIB, com a finalidade de coletar, catalogar, representar, organizar e disponibilizar a informação. Sua perspectiva era fundamentalmente política e ética, na medida em que a finalidade desse projeto era a promoção da informação com fins do estabelecimento da tolerância e da paz, evidentemente, sob uma perspectiva eurocêntrica. Para Otlet (2018, p. 5), a Biblioteconomia não era capaz de resolver os novos problemas informacionais, resultantes da quantidade de materiais publicados diariamente.

\footnotetext{
Para tornar acessível a quantidade de informações e artigos publicados todo dia na imprensa diária e nas revistas, para conservar os folhetos, anais, prospectos e documentos oficiais, para recuperar as matérias dispersas nos livros e para formar um todo homogêneo com essas massas incoerentes, são necessários processos novos, muito diferentes daqueles da antiga biblioteconomia, do modo como têm sido aplicados.
}

Já Ranganathan, conferiu cientificidade ao fazer bibliográfico e operacionalidade ao fazer documental a partir dos limites alargados da própria Biblioteconomia. Para o bibliotecário indiano, o profissional de biblioteca, consciente de seu papel social e sua função no processo democrático, não somente de distribuidor do conhecimento abstrato veiculado nos livros, mas também de agente inserido dentro de uma democracia educacional, era o profissional capaz de desempenhar as atividades exigidas pelo emergente universo documental. A Biblioteconomia era o tópos que alicerçava os saberes e fazeres atinentes à lida bibliográfica e documental.

Para consolidar seu projeto, Otlet necessitava fundar um novo espaço de discussão política e científica, sobre o qual diferentes países foram convocados à colaborarem nas ações documentais. Sua preocupação científica recaia sobre a Documentação, que era considerada a evolução da Bibliografia. Ranganathan, no que se referia à Documentação, tinha uma abordagem mais pragmática, afirmando se tratar de um conjunto de atividades análogas às atividades biblioteconômicas de catalogação e serviço de referência. No entanto, no que se referia a Bibliografia, Ranganathan desenvolveu um discurso mais científico, com função comunicacional essencial exercida pela chamada Bibliografia Social. O mundo do conhecimento, dos livros e das bibliotecas, atento às Cinco Leis da Biblioteconomia, daria forma a uma sociedade mais interessada nos produtos bibliográficos. 
A Biblioteconomia tem uma importância reduzida no Traité de Otlet, que se propunha justamente a fundamentar uma ciência nova para lidar com o documento e com o fluxo da informação. Imerso no paradigma positivista das Ciências Sociais, Otlet entendia que era preciso abandonar concepções da Biblioteconomia, com o intuito de criar concepções mais científicas para o universo documental. Assim, identificou um potencial na Bibliografia. Para o autor belga, essa disciplina, embora surgida no interior das bibliotecas, dissociava-se das mesmas num processo de inclusão de outros tipos documentais, para além do formato livro e, também, na busca por um método mais científico e objetivo à descrição dos documentos.

Ranganathan, em momento algum procurou se distanciar da Biblioteconomia, pelo contrário, a enalteceu em suas possibilidades de atuação e inseriu em seu bojo, por meio da implantação das Cinco Leis, a construção de uma da Bibliografia mais justa e democrática.

Otlet (2018, p. 5) afirmava que a Bibliografia era "a descrição e classificação dos documentos (livros, periódicos e artigos de revistas, etc.)" e implicava na análise de publicações e na feitura de seus resumos e representações. Ao relatar o histórico da Bibliografia, Otlet (2018, p. 53) apontava que

[...] a bibliografia se separa pouco a pouco da biblioteca. Ela nasce das necessidades, não de uma coleção determinada, que é atendida pelo catálogo, mas da ciência, desejosa de utilizar os livros onde quer que estejam armazenados. Para constituir um método - o da descrição dos livros e dos estudos sobre os conjuntos de livros - ela logo chega a ampliar a concepção que tinha do próprio livro até substituí-la pela noção de documento. A partir desse momento, apertada nos limites antigos, a bibliografia se afirma autônoma, do mesmo modo que a biblioteconomia, e critica seu particularismo. Lidando com a categoria do universal, logo influencia a ciência, a própria produção intelectual, à qual ela proporciona o meio de representar mais claramente sua própria universalidade.

Com o distanciamento da concepção biblioteconômica, o termo Bibliografia alcançou notável destaque no discurso otletiano, figurando, inclusive, no nome do Instituto Internacional de Bibliografia, que assim se manteve desde sua fundação, em 1895, até 1931, quando substituído pelo termo Documentação, passando a ser denominado Instituto Internacional de Documentação (IID). Note-se que a ideia de que a Documentação foi derivada da Bibliografia se reflete também nas nomeações do próprio Instituto, que em 1937 passaria a se chamar Federação Internacional de Documentação (FID) e em 1988, Federação Internacional de Informação e Documentação (com a manutenção da sigla FID). Essa substituição do termo "Bibliografia" por "Documentação" é símbolo de uma alteração também epistemológica para Otlet. 
Para Ranganathan, a Bibliografia, vista a partir do campo da Comunicação e tornada real a partir da Biblioteconomia, era o verdadeiro "estudo do livro" e se preocupava não somente com a produção de instrumentos ou com o entorno que envolvia o livro, mas principalmente com a produção do próprio livro e com seu consequente uso generalizado.

Talvez a grande semelhança entre Otlet e Ranganathan, no que se refere à Bibliografia, esteja notadamente no desejo de justiça e democracia. Porém, o fizeram de maneira diferente. Oltet deu protagonismo aos fazeres que envolviam os documentos com vistas à centralização de sua organização para permitir a equidade de sua recuperação. Ranganathan centralizou atenção no objeto livro de modo a torná-lo mais atrativo à grande massa de leitores. Para Ranganathan, o passado consolidou uma lógica aristocrática acadêmica que reproduzia o elitismo do livro. A ideia ranganathiana era induzir o cidadão comum ao consumo do livro, investindo num futuro bibliográfico mais justo. Temos, assim, em Otlet e Ranganathan um desejo de justiça e democracia, mas por caminhos diferentes. Na Bibliografia otletiana, o protagonismo do saber estava nos processos que envolviam o documento, ao passo que, na Bibliografia ranganathiana, o protagonismo estava no próprio objeto-livro.

De acordo com Otlet (2018, p. 11), o século XX carecia de uma ciência geral dos livros e dos documentos, de um tópos específico para pensar o fenômeno da informação registrada: "Precisamos agora não somente da bibliografia — a descrição dos livros —, mas também da bibliologia, isto é, de uma ciência e uma técnica gerais do documento”. Em outra passagem do Traité, o documentalista grifa novamente:

Eis que, agora, teve início uma nova fase. Não é nem aquela da biblioteconomia, nem da bibliografia, mas a do conjunto do livro e do documento: a documentação. Ambas são partes, mas partes ligadas a um corpo mais vasto, cuja existência as aumenta, as engrandece, as transforma (OTLET, 2018, p. 53).

Ranganathan (1952; 1973), diferentemente de Otlet, não investiu na delimitação de um outro tópos científico para superar a abordagem descritiva da Bibliografia, pelo contrário, localizou na Biblioteconomia todo o arcabouço teórico e prático necessário para dar os traços científicos de uma Bibliografia Social, superando, a partir da própria Biblioteconomia, aquela abordagem meramente instrumental da antiga Bibliografia.

A perspectiva otletiana de Documentação representava um novo estágio do conhecimento sobre o livro e sobre o documento. Um estágio de maior abstração, por isso, mais elaborado conceitualmente. A Documentação tinha a função de abarcar outras disciplinas, de 
congregar saberes e fazeres para uma construção de um arcabouço científico, positivo, que pretendia organizar as informações registradas, em nível mundial.

Conforme Otlet (2018), a Documentação dizia respeito aos conhecimentos teóricos e práticos relativos à sistematização de documentos, que se daria a partir da análise de dados, fatos e ideias fixados nos registros de informação. Este quesito metodológico Ranganathan trabalhou em outro momento de sua carreira, quando do desenvolvimento teórico da classificação facetada guiada pelo movimento analítico-sintético, a partir da análise das facetas de assuntos registradas nos livros ${ }^{1}$

Para Otlet, a Documentação diferia da Biblioteconomia porque não se restringia ao formato livro ou à instituição biblioteca, assim também da Bibliografia, pois extrapolava a descrição sintética dos documentos para desenvolver um conhecimento teórico e doutrinal para uma ciência geral que congregaria os saberes teóricos relacionados aos documentos e aos livros, a Bibliologia. Assim, a Documentação operaria sobre os registros de informação, na identificação dos elementos presentes nesses registros. No Traité, havia uma busca por um método, que era direcionado nas seguintes etapas:

$1^{\circ}$ coleta sistemática dos documentos; $2^{\circ}$ classificação que ofereça um esquema
comum a todas as divisões da instituição e sob cujos números apareça qualquer
assunto suscetível de interessá-la; $3^{\circ}$ sistema de redação de monografias e sistema de
fichas e folhas para ordenação vertical; $4^{\circ}$ sistema de pastas colocadas em
classificadores verticais, formando conjuntos organizados; $5^{\circ}$ confecção de fichas
catalográficas, desdobradas e bem detalhadas, de modo a mencionar os documentos
nas diversas séries fundamentais da classificação às quais se referem; $6^{\circ}$ equipamento
mecânico e processos químicos para proteger, confeccionar, reproduzir, multiplicar,
selecionar, ordenar e transportar os documentos." (OTLET, 2018, p. 7 )

Nessa linha, na perspectiva otletiana, a Documentação buscava "extrair do amontoado de documentos as verdades originais, importantes, não repetidas e colocadas no quadro sistemático das ciências", a fim de aproximar a comunicação da informação, via a informação registrada, a um nível ideal, no qual seria possível "realizar ao máximo para o homem condições cujo limite a ser atingido será a ubiquidade, a eternidade e o conhecimento intuitivo" (OTLET, 2018, p. 33 - 34).

Assim, Otlet discutiu, no Traité, principalmente a Documentação e a Bibliologia, sem conferir maiores destaques à Biblioteconomia. O termo Biblioteconomia ocorre apenas onze vezes na obra do autor belga, sendo que dentre essas, uma está no quadro sobre as classes da

\footnotetext{
${ }^{1}$ Para verificação das semelhanças entre os autores no movimento analítico-sintético, ver Sales et al. (2019).
} 
CDU, uma no título da seção "262.4 Técnica e organização das bibliotecas (bibliotecnia, biblioteconomia)" e outra na nota de rodapé 1. Ainda, outras ocorrências surgem apenas para pontuar a Biblioteconomia como elemento distinto da Documentação e da Bibliologia. Fora estas, o termo ocorre sem problematização, aprofundado ou mesmo caracterização. Nota-se que de fato não há uma discussão sobre a Biblioteconomia, contudo, há um discurso, que a coloca como um saber restrito ao domínio da biblioteca, com técnicas inadequadas aos documentos e a realidade do momento. Em um livro de 700 páginas (o Traité), a pouca referência ao termo "biblioteconomia" revela uma tentativa de silenciamento, da substituição deste por outras noções.

Já Ranganathan foi enfático ao ressaltar a Biblioteconomia em detrimento da Documentação, sugerindo que esta última seria, enquanto ciência, um invencionismo não fundamentado e forçosamente vinculado à chamada Ciência da Informação:

\begin{abstract}
The documentalists regarding themselve as belonging to a new profession. They look down upon the librarians and equate them with their old old image of a librarian in a public library, just putting date stamp and doling out books across the counter, or buying and accessioning books, and giving a strict account of all the books acquired [...] The documentalists claim that they are doing a piece of work totally different from that librarians. They do not at all want to call themselves as librarians. They do not want to include their subject in the term 'Library Science'. They even invent new names for their 'New Subject' such as 'Information Science" and 'Informatics'. They call themselves 'Information Scientists' in preference to 'Library Scientists'. This creates a self-deception in them, They imagine that changing the label on a bottle necessarily means change in its contentes (RANGANATHAN, 1973, p. 65).
\end{abstract}

Sobre a Bibliologia de Otlet (2018), tratava-se do espaço científico próprio do livro e do documento. Otlet atentou-se para o fenômeno informativo, voltado à construção do conhecimento artístico, filosófico e científico, e pretendeu abordá-lo não somente sob a dimensão técnica, mas também científica e teórica. Bibliologia era o destino positivista da Bibliografia, que se desafiava a atravessar os diversos campos do saber com a missão de organizá-los e impulsioná-los.

Assim, para Otlet, as Ciências Bibliológicas se configurariam como um campo universal de conhecimento, com uma linguagem própria (a ser desenvolvida), cujo escopo seria composto pela arte da escrita, da publicação e da difusão dos dados das ciências. Era "uma ciência e uma técnica gerais do documento" (OTLET, 2018, p. 11).

entendida como uma ciência geral, a Bibliologia reuniria sistematicamente os saberes da Retórica, da Biblioteconomia, da Bibliografia e da Tipografia, uma ciência que abrangeria 
“o conjunto sistemático, ordenado, dos dados relativos à produção, conservação, circulação e utilização dos escritos e documentos de todo tipo" (Idem).

A ciência geral do livro apresentava-se com caráter enciclopédico e universal, colocando-se ao lado de conhecimentos como a Lógica e a Linguística, pois levava em conta o conjunto de livros (no geral) e auxiliava o pensamento e a sua comunicação, na medida em que impunha suas normas. A Bibliologia prezava pela discursividade científica com uma preocupação ética, na medida em que compreendia o livro não apenas em sua unidade bibliográfica, atomizado, mas enquanto um objeto comunicador de ideias, cuja finalidade era a promoção da cultura.

A Documentação tinha em seu horizonte a evolução da sociedade em termos de inteligência, tal como visava as Ciências Sociais sob a epistemologia positivista. O conhecimento gerado dela, era denominado de Bibliologia: "A bibliologia se organiza, como ciência da documentação e do livro" (OTLET, 2018, p. 51). Para Otlet, o momento era de superação da Documentação, não no sentido da substituição, mas da ampliação do escopo, fortalecendo a dimensão científica, por meio do desenvolvimento de conhecimentos sobre o livro em sua forma geral. Em outras palavras, é possível observar no discurso de Otlet a intenção de constituir e/ou consolidar duas disciplinas científicas voltadas ao livro e ao documento que, de forma complementar e não excludente, se preocupariam com dimensões distintas do universo documental. A Documentação, voltar-se-ia aos aspectos teórico-práticos atinentes aos processos e técnicas que envolviam o documento, ao passo que a Bibliologia, numa perspectiva mais abstrata e geral, encarregar-se-ia pela construção de um arcabouço intelectual capaz de refletir sobre o conhecimento gerado pelo universo dos livros e dos documentos.

Podemos afirmar que havia no discurso de Otlet uma clara intenção de expansão disciplinar que, ao conferir certa emancipação ao universo documental, daria maior cientificidade a este mesmo universo. Numa narrativa marcadamente evolutiva, Otlet fortaleceu seu discurso com base em dois movimentos de expansão: da Bibliografia à Documentação (expansão da perspectiva descritiva para a perspectiva analítico-metodológica) e da Documentação à Bibliologia (expansão da ênfase metodológica para a ênfase epistêmica).

A título de ilustração, apresentamos no quadro a seguir uma síntese das informações analisadas e descritas neste trabalho: 
Quadro 1 - Comparando Otlet e Ranganathan

\begin{tabular}{|c|c|c|c|}
\hline & Bibliografia & Documentação & Biblioteconomia \\
\hline Otlet & $\begin{array}{l}\text { Área instrumental e } \\
\text { processual baseada em } \\
\text { uma abordagem } \\
\text { descritiva }\end{array}$ & $\begin{array}{l}\text { Ciência do documento } \\
\text { com ênfase analítico- } \\
\text { metodológica }\end{array}$ & $\begin{array}{l}\text { Disciplina que deveria } \\
\text { ser superada pela } \\
\text { Bibliologia }\end{array}$ \\
\hline Ranganathan & $\begin{array}{l}\text { Ciência do livro ligada } \\
\text { aos campos da } \\
\text { Comunicação e da } \\
\text { Biblioteconomia }\end{array}$ & $\begin{array}{l}\text { Atividade profissional } \\
\text { da Biblioteconomia }\end{array}$ & $\begin{array}{l}\text { Tópos científico da } \\
\text { Bibliografia e da } \\
\text { Documentação }\end{array}$ \\
\hline
\end{tabular}

Fonte: Elaborado pelos autores

Observamos que Otlet e Ranganathan apresentam perspectivas epistemológicas distintas para Bibliografia e Documentação, bem como para seus respectivos assentamentos topográficos. A cientificidade atribuída à Documentação de Otlet não é observada em Ranganathan, que preferiu conferir traços científicos à Bibliografia, entendendo a Documentação como um conjunto de atividades profissionais. Sob a égide das ciências sociais, ambos os autores conferem predomínio de discursos científicos em áreas distintas: Documentação para Otlet e Bibliografia para Ranganathan.

Outra distinção observada foi a importância dada à Biblioteconomia, pois enquanto Ranganathan a define como o próprio espaço científico capaz de desenvolver a Bibliografia (por meio das cinco leis) e a Documentação (por meio de trabalhos análogos à catalogação e ao serviço de referência), Otlet a define como limitada ao livro e à biblioteca e defende sua substituição pela Bibliologia.

\section{Algumas considerações}

Otlet e Ranganathan são importantes referências no campo da Documentação, Biblioteconomia e, posteriormente, da Ciência da Informação. Ranganathan apresenta vasta publicação nos diversos ramos da Biblioteconomia, com destaque para a área de gestão de bibliotecas e para a classificação bibliográfica. Otlet também é reconhecido por suas publicações, como o Traité, e seu legado para a organização da informação. Ambos conceberam sistemas de classificação próprios, a Colon Classification e a CDU, sistemas que tomam por princípio o método analítico-sintético. O desenvolvimento de tal inovação no processo classificatório diz respeito à crítica que ambos tinham à $\mathrm{CDD}$, que não se adequava às especificidades dos acervos. Otlet pretendia uma classificação mais específica na representação do assunto e mais ampla na cobertura, para lidar com documentos além dos bibliográficos. 
Ranganathan, em seu período de estudo na Grã-Bretanha, visitou diversas bibliotecas e constatou que, embora elas adotassem a CDD, na maioria das vezes imprimiam adaptações. Por isso, empenhou-se no desenvolvimento de uma classificação mais flexível que a de Dewey (PIEDADE, 1983).

Tiveram formações distintas: Otlet, sob uma tradição francófona, formou-se na área do Direito e era estudioso das Ciências Sociais. Ranganathan, matemático e bibliotecário, teve contato direto com o pensamento próprio de uma tradição anglófona. Otlet vivenciou a eclosão da Primeira Guerra Mundial, o que influenciou em seus projetos documentários utópicos, de promoção da paz mundial. Ranganathan assumiu o cargo de bibliotecário em Madras na época em que Gandhi lutava pela libertação da Índia, e defendia ideias como o acesso livre às bibliotecas e a democratização da educação.

O discurso do indiano é direcionado ao usuário, em atendê-lo da melhor forma possível. Há de fundo uma preocupação educacional na obra de Ranganathan, que perpassa as suas 5 leis e mesmo as possibilidades de adaptação da classificação bibliográfica pela Colon Classification. Otlet traz em seu discurso uma dimensão política, ética, de formar um espaço do conhecimento que promoveria a tolerância e a paz entre os povos.

Essas características acabam por influenciar suas respectivas concepções de Bibliografia, de Documentação e Biblioteconomia. Otlet não achava possível que a Biblioteconomia tomasse a dianteira da promoção da paz mundial pelo trabalho documentário, para ele, era necessária uma nova área, mais ampla, que não se restringisse às paredes da biblioteca. Por isso a Documentação, uma área internacionalizada, que nasceria para um novo mundo, permeado por tecnologias de informação e comunicação e pela necessidade de informações altamente especializadas. Ranganathan via nas bibliotecas o poder de transformação social, pelo conhecimento, pelos livros. Por isso seu trabalho hercúleo na constituição de uma base teórica para a Biblioteconomia, enquanto Otlet buscava alinhar sua produção com seu projeto internacional.

As diferenças aparecem nos conceitos analisados. A Biblioteconomia era, para Ranganathan, a ciência própria do livro, da leitura e da biblioteca. Cabia a ela adaptar-se às novas realidades de democratização do ensino para cumprir sua função de disponibilizar a informação e possibilitar o conhecimento. Para Otlet, era a Documentação e, mais genericamente, a Bibliologia que necessitaria ser inventada para dar conta dessa nova realidade 
informacional que surgia. Enquanto Otlet preteria a Biblioteconomia em nome de um novo projeto, Ranganathan reformulava-a, transformava-a às necessidades emergentes.

Com a Documentação ocorre algo semelhante, porém inverso, pois enquanto Otlet a valorizava em sua produção, dando-lhe fundamento, Ranganathan a compreendia como parte técnica da Biblioteconomia. Evidentemente, por ser mais novo que Otlet, Ranganathan foi impactado pelas ações do belga, tendo assistido o surgimento do Documentation Institute (1924) no Estados Unidos, a partir de um grupo derivado da Americam Library Association, e vivenciou a emergência da Documentação nos currículos e debates acadêmicos. Talvez por isso fundou em 1962 o Documentation Research and Training Centre no Indian Statistical Institute de Bangalore, na Índia.

Com relação à Bibliografia, os pensadores também divergiam. Otlet a submeteu ao seu projeto, colocando-a como precursora da Documentação, por compreender nela a ruptura com a biblioteca, ou seja, a autonomia dos processos bibliográficos dos bibliotecários. A Documentação ratificava essa condição, tornando-se uma disciplina independente e nova para lidar com os fenômenos documentais. Com relação a Ranganathan, há que se destacar que, por sua formação inglesa e por ser mais novo que Otlet, teve acesso à textos que institucionalizaram a Bibliografia como área a partir do final do século XIX, na Inglaterra (ROBERSON, 2001). Nota-se isso inclusive pelos termos oriundos de estudiosos da Bibliografia citados por Ranganathan (1952), tais como "bibliografia enumerativa", "bibliografia analítica", "bibliografia histórica", dentre outros. Ainda, cabe destacar que no Traité, parte dos estudos relativos à Bibliologia, foi levado adiante por essa Bibliografia, que se dedicou à investigação dos textos e dos documentos a partir de elementos históricos, sociológicos e simbólicos (McKENZIE, 2018).

Otlet e Ranganathan tinham a preocupação em alinhar as técnicas documentais e bibliotecárias à metodologia científica. Análise e sínteses, processos constituintes dos métodos de classificação dos pensadores, eram procedimentos necessários nos processos de investigação científica. Dotar cientificidade à Documentação e a Biblioteconomia foram as propostas dos pensadores, que embasaram teoricamente as respectivas disciplinas. Ambos nasceram no século XIX e morreram no XX, e encararam transformações tecnológicas, políticas e sociais radicais, que conferiram importância à informação. Ambos entendiam a informação como elemento central na democratização e na melhoria das condições culturais, sociais e políticas. Por isso, desenvolveram meios para garantir o acesso à informação. 


\section{Referências}

ARAÚJO, A. V. F. Pioneirismo bibliográfico em um polímeta do séc. XVI: Conrad Gesner. Informação \& informação, Londrina, v. 20, n. 2, p. 118-142, 2015.

BURKE, P. Problemas causados por Gutenberg: a explosão da informação nos primórdios da Europa moderna. Estudos avançados, São Paulo, v. 16, n. 44, p. 173-185, 2002.

CRIPPA, G. Cassiodoro e as Institutiones Divinarum Litterarum como fonte histórica para a discussão sobre práticas bibliográficas e organização do conhecimento. Informação \& informação, Londrina, v. 20, n. 2, p. 86-117, 2015.

LARA, M. L. G. Conceito de bibliografia, ou conceitos de bibliografia? Informação \& informação, Londrina, v. 23, n. 2, p. 127-151, 2018.

MANGUEL, A. A biblioteca à noite. São Paulo: Companhia das Letras, 2006.

McKENZIE, D. F. Bibliografia e a sociologia dos textos. São Paulo: EDUSP, 2018.

ORTEGA, C. D. Relações históricas entre biblioteconomia, documentação e ciência da informação. Datagramazero: revista de ciência da informação, Rio de Janeiro, v. 5, n. 5, 2004.

OTLET, P. The science of bibliography and documentation. [1903]. In: RAYWARD, W.B. (Ed.). International Organization and Dissemination of Knowledge: selected essays of Paul Otlet. Amsterdã: Elsevier, 1990. p. 71-86.

OTLET, P. Documentos e documentação. Trad. de Hagar Espanha. Paris, 1937. Introdução aos trabalhos do Congresso Mundial da Documentação Universal, realizado em Paris, em 1937. Disponível em: http://www.conexaorio.com/biti/otlet/index.htm. Acesso em: 01 ago. 2020.

OTLET, Paul. Tratado de documentação: o livro sobre o livro teoria e prática. Brasília: Briquet de Lemos, 2018.

PIEDADE, M. A. R. Introdução à teoria da classificação. 2. ed. Rio de Janeiro: Interciência, 1983.

RANGANATHAN, S. R. Social bibliography or phisical bibliography for librarians. Delhi: University of Delhi, 1952.

RANGANATHAN, S. R. Documentation: genesis and development. Nova Delhi: Ess Ess Publications; Bangalore: Sarada Ranganathan Endowment, 1973.

RAYWARD, W. B. The universe of information. The work of Paul Otlet for Documentation and International Organisation. Moscow: VINITI, 1975.

ROBERSON, M. A brief history of bibliographies. Social Epistemology, Abingdon, v. 15, n.1, p. 5-8, 2001. 
SALES, R. Ranganathan e a mudança no trajeto das classificações de biblioteca. In: LUCAS, E. R. O.; CORRÊAA, E. C. D.; EGGERT-STEINDEL, G. As contribuições de Ranganathan para a Biblioteconomia: reflexões e desafios. São Paulo: FEBAB, 2016, p. 57-71.

SALES, R. et al. The contribution of James Duff Brown to the analytic-synthetic method: comparisons with Otlet, Kaiser, and Ranganathan. NASKO, Philadelphia, v. 7, p. 1-6, 2019.

SALES, R.; GUIMARÃES, J. A. C. O método analítico-sintético de Julius Kaiser: um pioneirismo para o tratamento temático da informação. Transinformação, Campinas, v. 29, n. 2, p. 125-139, 2017. DOI: 10.1590/2318-08892017000200001. Acesso em: 15 ago. 2020.

SALES, R.; MURGUIA, E. I. Instaurações discursivas da organização do conhecimento: H. E. Bliss e a International Society for Knowledge Organization (ISKO). Ciência da Informação, Brasília, v.44 n.3, p.396-415, 2015.

SILVA, A. M; RIBEIRO, F. Das ciências documentais à ciência da informação: ensaio epistemológico para um novo modelo curricular. Porto: Afrontamento, 2002.

SORDET, Y. Da argila à nuvem: uma história dos catálogos de livro (II milênio-século XXI). São Paulo: Ateliê, 2019.

WOLEDGE, G. Historical studies in documentation: 'bibliography' and 'documentation': words and ideas. Journal of Documentation, London, v. 39, n. 4, 1983.

YOGESHWAR, R. S. R. Ranganathan: pragamatic philosopher of information science: a personal biography. Mumbai, Índia: Bharatiya Vidya Bhavan, 2001. 